\title{
Wayang Kulit Kelantan: The Challenges Between Traditional and Digital Media in Puppetry Theatre
}

\author{
Dahlan Bin Abdul GHani \\ University Kuala Lumpur, malaysian Institute Information Technology \\ Creative Multimedia Section, 1016 Menara Bandar Wawasan \\ Jalan Sultan Ismail, 50250 Kuala Lumpur, MALAYSIA \\ Dahlan@miit.unikl.edu.my
}

Recibido: 21 de septiembre de 2010

Aprobado: 6 de abril de 2011

\begin{abstract}
Traditional Malay theatre arts such as Wayang Kulit Kelantan or Shadow Play puppet Kelantan in Malaysia has been a form of entertainment. Unfortunately, this shadow play puppet has lost it touch and is slowly fading among the society in Malaysia. This paper will focus both on the traditional method and the animation method to create Kelantan shadow play 3D visualization digital puppetry. The paper will begin with some research on previous work related to traditional shadow play puppet and will name some efforts made to digitizing this type of performance. The paper will also look into the results of comparing the two techniques. The final section of the paper will attempt to highlight the challenges and future aspects of animation and traditional shadow play that would be significant in helping bring back the popularity of this Malaysian performing arts masterpiece.
\end{abstract}

Key Words: Wayang Kulit Kelantan, Shadow play, 3D Visualization puppetry.

Bin Abdul Ghani, D. 2012: Wayang Kulit Kelatan: The Challenges Between Traditional and digital Media in Pyppetry Theatre. Arte, Individuo y Sociedad, 24(1), 135-146

Contents: 1. Introduction, 2. Related work, 3. Methods of Shadow Play, 4. Results, 5. Conclusion. Referencias

\section{Introduction}

This study focused on shadow play or Wayang Kulit Kelantan, one of four main forms of Wayang Kulit in Malaysia. Wayang Kulit Kelantan was known and enjoyed by Malays who lived in rural areas. Both its dramatic and musical aspects, existing only in the oral tradition, were transmitted to young performers, generation after generation (Mastusky, 1997). Nevertheless, in the urbanized West Coast of Malaysia, shadow play has traditionally had very little significance as a form of entertainment. Moreover, since 1957, there has been no attempt to provide a growing, nurturing environment throughout the country for traditional arts from rural areas (Osman 1974). Wayang Kulit Kelantan today distinctively reflects traditional Malaysian culture from its linguistic and the shown elements.

It can be stated that Wayang Kulit Kelantan in Malaysia is threatened with imminent extinction. Amin Sweeney's research in the late 1960's confirmed the existence of more than 300 Dalangs for shadow puppeteer (Sweeney, 1972). The gradual invasion of modern forms of entertainment, as mass media, in the traditional 
villages of Kota Bahru and Tumpat areas in Kelantan for example, provided people with films (cinemas), radio, \& televisions programmes, which drew them away from their favourite forms of traditional enjoyment in the evenings. The shadow play or Wayang Kulit Kelantan (see picture 1.0) has lost its hold on the masses who were never systematically educated to appreciate traditional theatre and music. (Jaya Tilakasari, 1994)

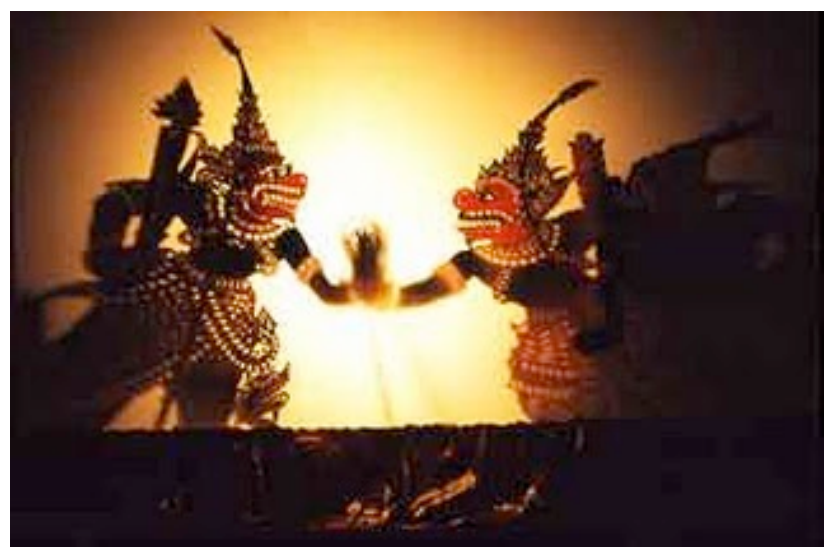

Picture 1.0 Performance of Traditional Wayang Kulit Kelantan

From the perspective of Islamic religion, holding a shadow play theatre has also brought controversy not only in Malaysia but also some other Islamic countries around the world. According to the Ghulam Sarwar Yousof (1997) "The State of Kelantan has banned Wayang Kulit"). The reason behind this banning is the contradictions between this type of entertainment and the Islamic doctrine.

There is an urgent need to preserve this form of art from dying out. It seems clear that, in the current situation, puppet shadow play is unlikely to last long in Malaysia unless it receives some kind of strong official support (Ghulam Sarwar, 2004). This heritage needs an alternative media or style to be promoted. It needs to be digitized or brought onto computer or cinema screens (Ghouse, 2001).

It is evident that the art of shadow play is slowly disappearing also due to the lack of interest in it of the younger generation. There is a need then to preserve, promote and provide greater accessibility to, which we consider, a master piece. This can be done by using nowadays technologies such digital media. Unfortunately, not many initiatives are being carried out in virtual or digital shadow play presently, even though extensive research has been carried out in other virtual or digital storytelling. Therefore, this paper will focus and discuss the relationship between Wayang Kulit "animation" output and traditional methods, also taking into account some variable aspects between animation \& Wayang Kulit fundamentals: puppeteer, frame by frame, shadow or screen projection (Kelir) and character design. 


\section{Related work}

Puppets are a powerful interface to fantasy and creativity. Its use provides a great potential to educators when working with children; their immediateness and simplicity makes them friendly and engaging. Moreover, puppets provide children with a mean for expressing and experiencing emotions and interacting with other pairs (Mayora et alt. 2009).

Mareeya and Sunchanee researched on using design and create multimedia enhances storytelling understanding for Thai skills seventh grade students through puppet entertainment. From this research, the seven grade students interested in the media over learning from the article by 25 percent due to multimedia video technique by introducing puppet characters that encourage the students' behavior to learn more (refer picture 2.0) The students are able to recognize the viewing place more effective from the video animation, the usage of language that are familiar for students and also the sound or music used for puppet entertainment makes the students learn while they enjoy the play. (Mareeya \& Sunchanee, 2010)

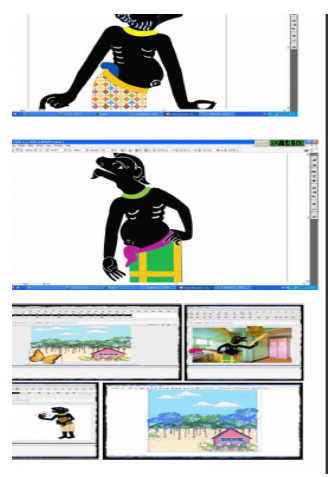

Picture 2.0 Puppet used for Multimedia video for seventh grade students in Thailand

Copyright@2nd International Conference on Computer Technology and Development, 2010

Another approach developed by Oscar Mayora was the immersive interactive integrated system for story-creation and storytelling, aimed at young children through the use of hand puppet system or i-Theatre (picture 3.0). Based on the use of real puppets and other tangible representations of screenplay elements, i-Theatre allows children to have full control of the story (Mayora et Al. 2009). This is relevant according to the children needs regarding interaction and technology control, social experience and expressive tools (Druin et Al, 1999). It is relevant also with the fact that technology should support children's curiosity, love for repetition and need for control (Druin Solomon, 1981).

Selected objects (in this case playing cards) are collected on a bowl equipped with an antenna that reads the embedded RFID tag, allowing the system to recognize the user's choices and to set up the virtual puppet theatre. The tangible interfaces proved to be powerful tool to fully exploit the physicality of the puppet theatre with all its creative richness. Moreover, children's confidence with puppets allows reducing the barrier to learn this new interface in i-theatre. 

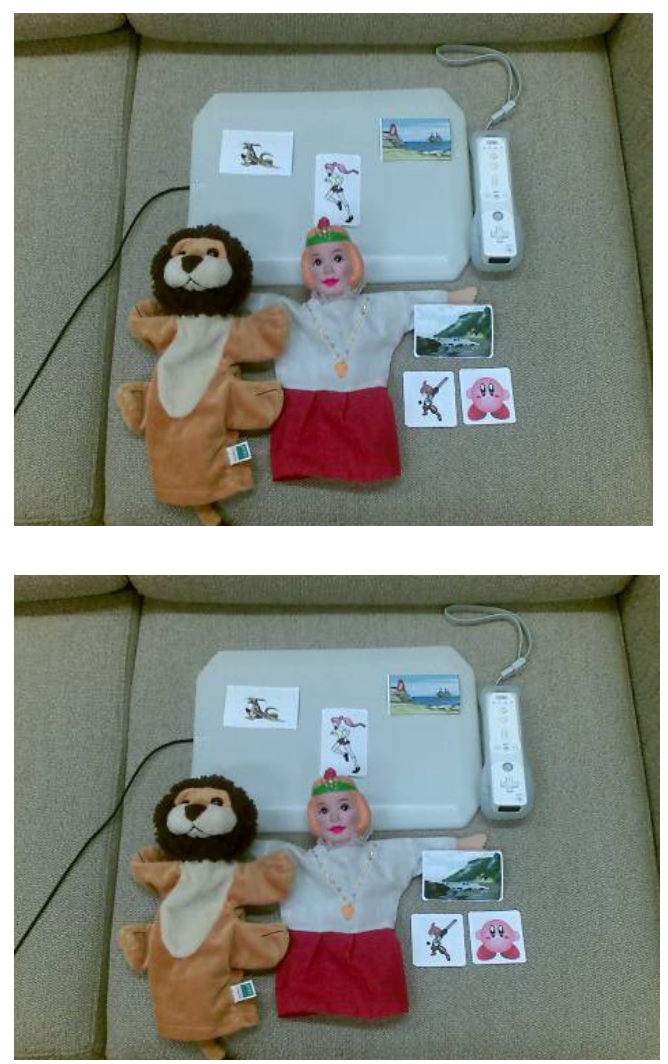

Picture 3.0 I-theatre system uses hand puppet character (C ICST Institute for Computer Sciences, Social Informatics and Telecommunications Engineering, 2009

In 1996, the University Malaysia Sarawak (UNIMAS) carried out a research project known as 'Wayang Virtual'. In general, the research was inspired by the tradition of storytelling using pictures in the Southeast Asia (shadow play or traditional Wayang Kulit). This project attempts to explore and combine traditional Wayang Kulit with the 3D model, using IRIS showcase running on Silicon Graphic software, real time Musical Instrument Digital Interface (MIDI) performance and traditional Wayang Kulit as well as traditional music live performance. The 'virtual' version of the traditional puppet or 'shadow' is combined with a 3D animated figure controlled by the Dalang with a mouse on a SGI machine and later projected to the white screen. According Hasnizam (2007), Wayang virtual retained many of Wayang Kulit originality, including the use of traditional puppets, live traditional music performance and narrative aspects.

Overall, there are efforts in digitizing the puppet concepts and research have already being established to look further into the aspect of visual materials, definition and terminology in wayang kulit performance. As well as to explore further the re- 
lationship between visual and virtual puppets parameter that, governed by modes of live interactive and real-time story telling in our traditional 'picture recitation'. It is also believed that wayang kulit are among the oldest form of performing art in Malaysia and that can be recognized as a form of multimedia entertainment.

\section{Methods of Shadow Play}

\subsection{Traditional Method}

The word "puppet" comes from the Latin pupa, meaning "doll." But puppets are more than dolls, for in them is the illusion of life. According to Ghazali Abdullah(2007), Wayang Kulit Puppet or Shadow Play reflects the traditional symbolism to express emotion, dream, and ambition, in a creative way, through the communication process of a shadow reflected on a white screen (Kelir)(Ghazali Abdullah, 2007). Wayang is a generic name meaning "a flat or rounded puppet used in presenting a play" (Amin Sweeny, 1994). The terms was perhaps associated exclusively in usage among Europeans as the shadow play because the flat puppet provided the most popular type entertainment almost excluding interest in other types of puppetry. Shadow Play Kelantan has been able to preserve the magical and aesthetic character of the performance much more than the wayang Java which are adapt with urban needs entertainment.( Jayadeva TilaKaSari,1999)

According to Amin Sweeney (1972), in Malaysia, the shadow play is performed on a stage known as panggung. The screen is slightly positioned towards the audience, seated on the ground during the performance. The shadow play story usually takes four to five nights to complete. The traditional of this aspect are mainly regards as a medium of aesthetic among the society. The light or "pelita" in placed behind the screen at eye-level height with the puppeteer or Dalang sitting on the floor. The Dalang manipulates the puppet between the lamp and the screen, casting shadows on the screen as he relates a tale (picture 3 ).

There are two techniques the Dalang use while playing Wayang Kulit. These are the puppets motion handling and coordination technique and the story expending technique. These techniques are based on format inside aturan Dalang or guided puppeteer technique, which only can be used by in a formal practice by the Dalang. The result is very interesting because almost every Dalang in different play has same similarity of techniques. The education system for Dalang or puppeteer contains sufficient subject learned that covers techniques in playing and method on shaping the Dalang personality. 


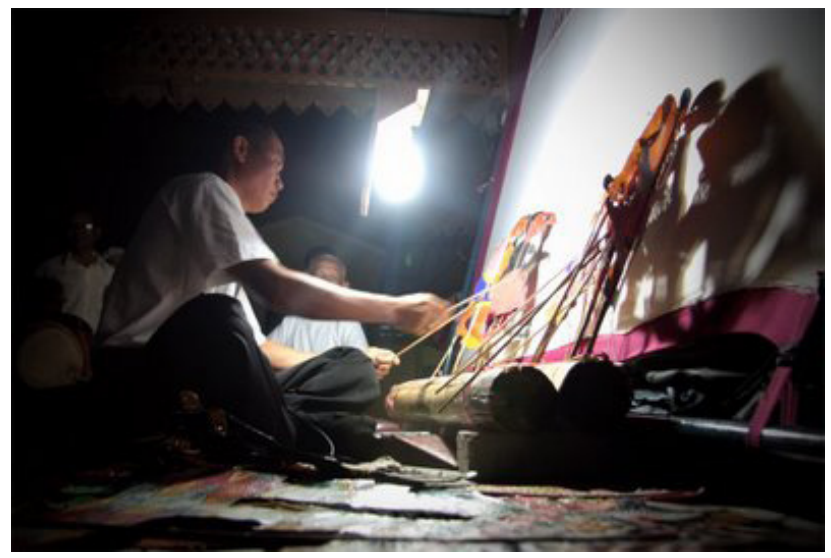

Picture 4.0 The Puppeteer controls the puppets on the white screen helped by the light projected by the lamp behind

A shadow is an image cast by an object intercepting or impeding light or the comparative darkness formed when such an object a difference in intensity of light on any surface (Shanon, 2004). Shadows have often been regarded as having magical qualities and have strong cultural, religious and scientific dimensions (David Curell,2007).

A typical scene in a shadow play is usually composed by animated characters and other environmental objects. But indirectly, the shadows moving on the screen are referred as frame by frame motion. It is a 2 dimension figure held against a translucent, lit screen that allows the audience on the other side see shadows thus created. For a fighting scene, the action of the puppets can be very dramatic, sometimes supplemented by special lighting effects. Performance is also accompanied by singing and musical performance. Musical in wayang kulit fulfils a variety of functions, from merely conveying meaning or emotion to supporting what is shown on the screen which will impact greatly on the audience. During the performance of wayang kulit, the musicians are placed behind the kelir (white cotton screen) together with the Dalang who will act as the musicians' conductor.

Barrie \& Rockliff (1960) described the impact of the traditional shadow play puppet show by highlighting the difference between the puppet placed on a flat table and the shadow cast on the screen, suggesting that the strength and impact of the solid shadow is quite different from that of the object. During the performance, the puppeteer will act as the story teller (Tok Dalang) and will manipulate the figure or patung by gliding the figures between the changing lamp light and the screen. He will also speak all the parts by changing his voice to suit each character; he will occasionally add a short song sequence as well (Sheppard 1986). 


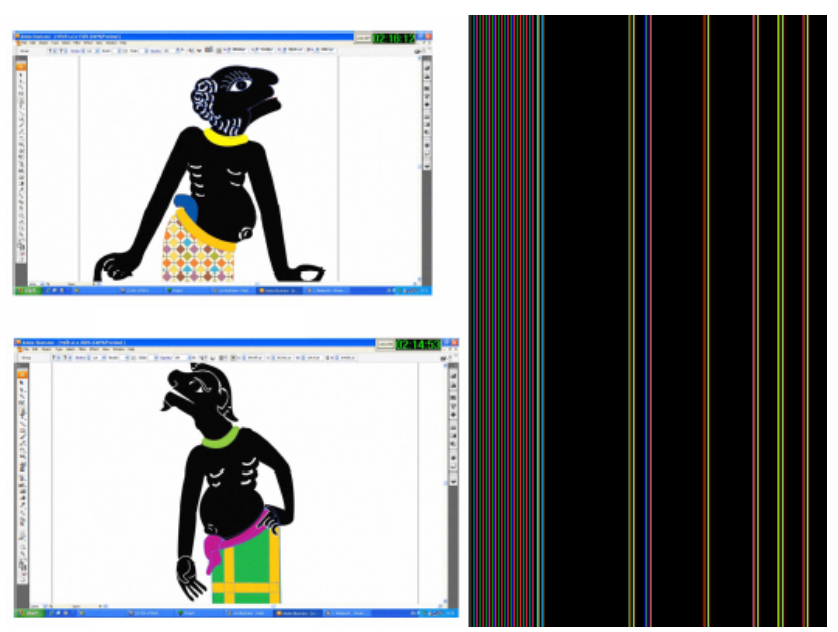

Pic 2.0 Refers to Shadow Play - Wayang Kulit Kelantan Influences

An interview with Malaysia's famous puppeteer En Mohd Nasir from ASWARA 2010 (The academy of Arts \& Culture Malaysia) believes that the influences between Hindu, Siam \& Malay culture into shadow play puppet character especially in Kelantan are being a strong significance performing arts culture in Malaysia (refer pic 2.0). According to Leslee Arch(2010), In every culture, man has created stories and myths to explain the forces surrounding him and the fears, hopes, and dreams he carries within(Leslee Arch,2010). Overall, the traditional style of Wayang Kulit Kelantan until today remains its form and presentation in order to preserve the heritage from endangered. The play is still a demand but values and attribute for Wayang Kulit Kelantan should always be maintained even due to modernization and globalization may affect slightly at this entertainment in future.

\subsection{Animation Method}

Computer graphics is a powerful medium used to communicate information and knowledge. Computer graphics is the pictorial synthesis of real or imaginary objects from their computer-based models. A related field is image processing which is the reconstruction of models of 2D and 3D objects from their pictures (Foley et al, 1996). Traditionally, computer graphics is framed within the well recognized disciplines of computer science, electrical and computer engineering, and art and design. Wayang Kulit Kelantan or Shadow Play Puppet Kelantan are played in 2D environments. Puppetry, the emerging forms of digital puppetry and puppet like talking toys are all about 'control' in two important senses. (Ian Grant, 2008)

Using the traditional method, wayang kulit Kelantan is performed by a puppeteer, in animation control by the animator. In order to consider digitizing traditional puppetry into digital puppetry, the study of $3 \mathrm{D}$ structure to the puppetry scene are indispensable in making the final animation, and requires the animator's imagination and creativity from the previous traditional puppetry (Ken-ichi Anjyo,2001). 
Character design for 3D visualization requires modeling, rendering, lighting, camera, and texture in animation environment. In $3 \mathrm{D}$, perspective is the attempt to fool the eye into understanding depth, distance, and relative space which sometimes the perspective behind of it is known as "ray tracing" (Adam Watkins, 2001) As mentioned earlier, the conventional method of Wayang Kulit Kelantan is 2-Dimesnional (2D) perspective view (picture 6.0) due to the cartesan coordinate involved of the figure are $\mathrm{X} \& \mathrm{Y}$ coordinate. But in $3 \mathrm{D}$ computer graphics, the $\mathrm{X}, \mathrm{Y} \& \mathrm{Z}$ are 0 and this fact allows the animator and the audience to view the depth in each shadow play puppet.

The puppet character design can be modeled using Non-Uniform Resource Boolean Spline \& Polygons in 3D software (NURBS). Polygon models design for the digital puppetry (picture 6.0) are the least taxing on a computer's processing muscles. The idea behind polygon modeling is that the computer takes two dimensional shapes (squares or triangle) and organizes them into digital space to form the shells of 3D shapes. NURBS consist of control points (vertices) that are offset from the actual interpolation.

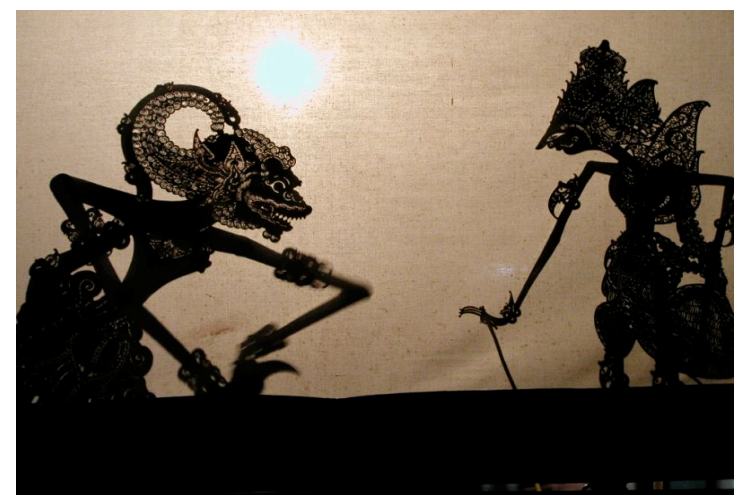

Pic 5.0 The Wayang Kelantan Puppet Character in 2D perspective view

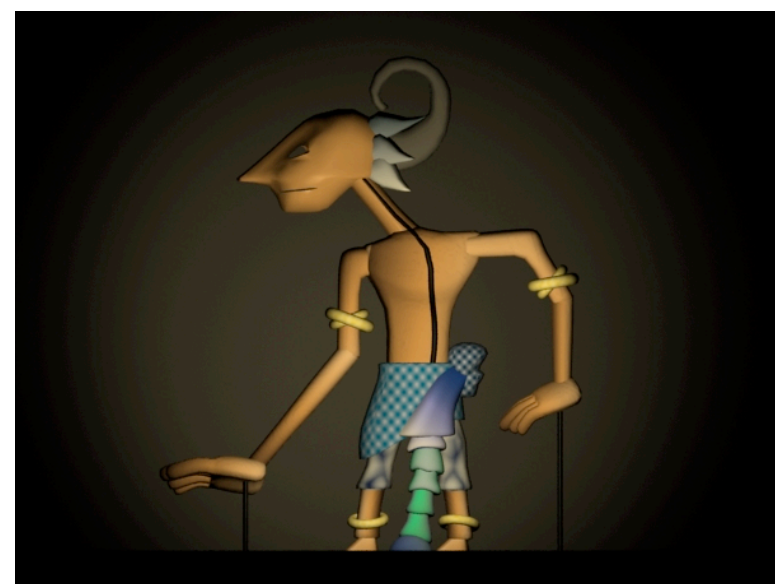

Pic 6.0 The Wayang Kelantan Puppet Character model in 3D 
In 3D digital puppetry, the movement of the character has to be animated using key frames in MAYA 3D software. Lighting, camera, texturing, character rigging, and facial expression are possible to be implemented on digital puppetry. Computer software such as Autodesk 3D Studio Max \& MAYA is a powerful 3D software to develop digital puppetry animation. High end computers with powerful hardware are needed in order to achieve the realism effects of the traditional puppetry theatre.

\section{Results}

\begin{tabular}{|c|l|l|l|}
\hline Table & \multicolumn{3}{|c|}{ Wayang Kulit Kelantan ( Shadow Play Puppetry) } \\
\cline { 2 - 4 } Head & \multicolumn{1}{|c|}{ Items } & \multicolumn{1}{|c|}{$\begin{array}{c}\text { Conventional } \\
\text { Character Puppet Design }\end{array}$} & $\begin{array}{c}\text { Digital Puppetry } \\
\text { Hodel in 3D Software } \\
\text { using Nurbs \& Polygons } \\
\text { which are complicated }\end{array}$ \\
\hline 2. & Animation & $\begin{array}{l}\text { - Animate manually by } \\
\text { puppeteer using both hands } \\
\text { and props } \\
\text {-Distinctive shadow } \\
\text { distortion }\end{array}$ & $\begin{array}{l}\text { - Using key frame in } \\
\text { 3D software }\end{array}$ \\
\hline 3. & Lighting & $\begin{array}{l}\text { Basics props , lights and } \\
\text { kelir }\end{array}$ & $\begin{array}{l}\text { Needs High computer } \\
\text { RAM especially Rendering }\end{array}$ \\
\hline 4. & Texturing \& Camera & $\begin{array}{l}\text { Manually craft \& colored } \\
\text { Viewers has alternative to } \\
\text { choose the view }\end{array}$ & $\begin{array}{l}\text {-Needs to apply realistic } \\
\text { texture, UV } \\
\text { - Camera provides various } \\
\text { movement/ angle }\end{array}$ \\
\hline
\end{tabular}

Table 1.0 The effective element is Wayang Kulit (Shadow Play) 3D Puppetry

In order to evaluate the effectiveness of both conventional puppetry \& digital puppetry, we did some experiments and observation so that we could compare the results of the puppetry entertainment using conventional style and 3D animation computer graphics. In terms of character design ( table 1), the traditional option seems to be more convenient. Wayang Kulit Kelantan puppets are carved out of thinner cow skins and painted with batik colors thus are able to cast colorful shadows on screen. For instance, a basic Wayang Kulit Kelantan set consists of 65 - 120 puppets representing the principal characters from the Ramayana. Designing so many characters digitally would take an enormous amount time.

In traditional wayang puppetry, the puppeteer or Dalang in wayang kulit Kelantan will move the puppet character with both of his hands and will be able to create distinctive shadow distortions which are visible in many scenes especially during the Dalang Muda Episode and in fighting scenes. This is not much seen in other Wayang Kulit performance. In 3D digital puppetry it would be difficult to handle key frame length and accuracy for each movement of the puppet. Body movement, eyes, mouth (lip-sync), and facial expression are complicated to animate as well. From the 
lighting point of view, our observations are based on two techniques, the traditional shadow play puppet lighting which creates the mood and also the atmosphere and the artificial computer 3D graphics software. In the first case, the light source is a lamp normally suspended from the top roughly at the centre of the screen reaching to about the height of the Dalang's face when he is doing his performance in his across-legged sitting position (picture 4. 0). In 3D computer graphics programs, it would seem difficult to get the exact light, color and mood as in the traditional style. An animator must understand the types of light, light reflection source, light intensity, ambient, shadow and other elements in order to gain the correct lighting for the shadow play puppet theatre. When the rendering occurs it could also causes the computer performance to slow down due to the over use of memory or Random Access Memory (RAM)

Puppet texturing craft is carefully designed with the right amount of colour, texture, etc. Colour symbolism is used in the puppet design, especially in the case of noble characters. In 3D digital puppetry, the quality of texture of these puppets must be also correctly detailed. UV mapping has to be done accurately, as well as the light source that will influence the texturing reflection of the puppet model in 3D. This technique is complex and its realism effect, compared to the traditional or conventional method for puppet theatre entertainment, could be questionable (table 1.0)

Concerning the camera, it can be said that the animation camera has various positive attributes in terms of movement; it brings real action to viewers, depth of field, tracking, dolly could be done in 3D environment. This is an added advantage compared to traditional puppetry in which some viewers have a limited option to view the puppet show, for example the audience sitting at the back of the theatre. Lastly, realism is another important point to consider when talking about $3 \mathrm{D}$ animation as it helps open new methods or technology for its implementation.

The biggest issue that rises in computer graphics especially in 3D is realism. Even though, the traditional or conventional style of shadow play or wayang kulit Kelantan will always be a preferable choice, using the latest technology in 3D computer graphics could also bring the shadow play puppet into a more realistic look and mood; this can help the audience to accept it in the future. Techniques such as Motion Capture, OpenGL, and 3D stereoscopic camera would be an advantage in the digital puppetry entertainment.

\section{Conclusion}

We hope that this research will contribute knowledge in the future develop of puppet entertainment and more related work could be develop in steps to preserved this tremendous performing arts value especially to Malaysian people and also people from all around the globe. Should the Wayang Kulit Kelantan face extinction as forecasted by the researchers, our future generations will be able to see this traditional art form in digital puppetry animation, video, virtual reality, augmented reality and many other information technology as a new alternative platform. 


\section{Acknowledgement}

The author would like to personally thank my wife Norashikin for the help and support, Prof Dr Mohd Sidin Ahmad Ishak, my PHD supervisor, En Nasir from ASWARA, friends and family members for the support giving the support in accomplishing this research.

\section{References}

a) Books:

Patricia Matusky, 1997 "Malaysian Shadow Play \& Music" Asian Centre Press, Mohd Taib Osman, 1974 "Traditional Drama \& Music of Southeast Asia",

DewanBahasa Pustaka Press, Kuala Lumpur.

Book Ministry of Culture, 2004, Wayang Kulit. Arts and Tourism,Malaysia, Amin Sweeney, 1972, Malay Shadow Puppets. The Trustees of the British Museum

Books.

Jayadeva TilaKaSari, 1999, "The Asian Shadow Play",Vishva Lenka Press Books, Sri Lanka.

Druin, A., Solomon, C, 1981 Designing Multimedia Environments for Children. John Wiley \& Sons, Inc.

David Curell, 2007, Shadow Puppets \& Shadow Play Puppets, Crowood Press Ltd, London.

Adam Watkins, 2001, 3D Animation: From Models To Movies, Book : Charles

Rivers Media Inc, Rockland Press US.

FOLEY, J. D., VAN DAM, A., FEINER, S. K. AND HUGHES, J. F. , 1996 Computer

Graphics: Principles and Practice. Addison-Wesley: Reading, MA.

b) Journal articles:

Prof Ghulam-Sarwar Yousof, 1997, Angin Wayang (Hamzah Awang Mat)

Kementerian Kebudayaan, Kesenian \& Pelancongan Malaysia, Printed byAsni

Sdn Bhd Press, Kuala Lumpur.

Ghulam-Sarwar Yousof, 2006, The Malay Shadow Play as a Continuing, Changing Tradition Dimensions of Shadow Play in Malay Civilization. UiTM, Malaysia.

Mohd Ghouse Nasaruddin., 2001, Wayang Kulit Dalam Era Globalisasi, Wayang

Dalam Bayang. USM, Penang, pp : 12- 18.

Mohd Ghazali Abdullah, 2007, Symbolism in Wayang Kulit Kelantan (Shadow Play Puppet Kelantan), Journal: ASWARA, Volume 2.

Leslee Arch, 2010, The Art Of Contemporary Puppet Theatre, Article at Katonah Museum Art, UK.

Oscar Mayora, Cristina Costa, and Andrei Papliatseyeu, 2009, iTheater Puppets

Tangible Interactions for Storytelling, Journal: ICST Institute for Computer

Sciences, Social Informatics and Telecommunications Engineering. 
Mare eya Binmalee \& Sunchanee, 2010, Learning Behaviour Using Multimedia Techniques Enhance Understanding for Thai skills:The Laboratory Research in the Seven Grade, Journal: 2nd International Conference on Computer Techno and Development.

Druin, et al. 1999, The Design of Children's Technology. Moran Kaufmann Publishers, Inc. San Francisco.

Dr Hasnizam Abd Wahid, 2007, The Integration and an Experiment of a Traditional Wayang Kulit Performances and Electro Acoustic Music, University Malaysia Sarawak, - Leicester (UK) - The Language of Electro acoustic Music.

Sheppard M, 1986, A Royal Pleasure Ground Malay Decorative Arts and Pastimes, Oxford University Press Pte. Ltd. Singapore.

Ian Grant, 2008, Silhouette \& Digital Puppetry Thames Valley University, London, Journal UK.

Ken-ichi Anjyo, 2001, Bridging the Gap Between 2D and 3D:A Stream of Digital Animation Techniques, Proceedings of the 9th Pacific Conference on Computer Graphics and Applications, IEEE Journal.

c) Online Articles:

Shahnon, The Art of Shadow Play, Online resource: http://www.shahnon.com/ shadowplay/design.htm.

Book chapters and collective works: Author or authors (as above), year and colon; title of the work or chapter, period, followed by "In" name initials period and director, editor, or coordinator's surname followed by (Dir(s), Ed(s)., or coord.(s) (in parenthesis); Book title in italics, chapter pages (in parenthesis), period; Location, comma and editorial, period. Example:

Freeman, N. H. 2000: Development of the conception of children's art. In M. Hernández Belver \& M. Sánchez Méndez (coords.): Artistic education and children's art(pp. 59-65). Madrid, Fundamentos.

c) Journal articles: Author or authors (as above); year and colon; title of article, period; journal name in italics, comma, volume in italics, comma; number (in parenthesis), comma, and initial and final page numbers of the article, period. Example:

Castro, F. 2002: Skirmishes. Art, Individual and Society, 14, 105-121. 